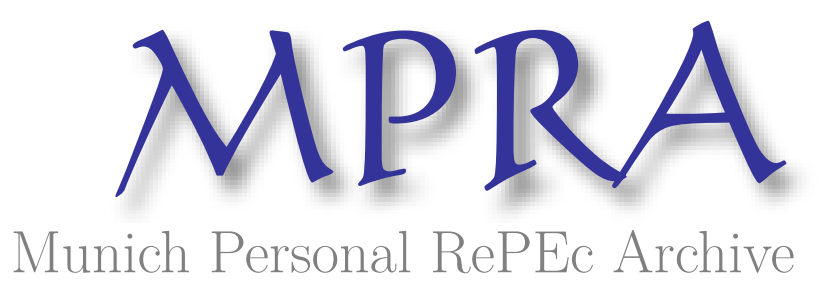

\title{
Measuring the size of the shadow economy using a dynamic general equilibrium model with trends
}

Solis-Garcia, Mario and Xie, Yingtong

Macalester College, University of Wisconsin-Madison

3 January 2017

Online at https://mpra.ub.uni-muenchen.de/78968/

MPRA Paper No. 78968, posted 06 May 2017 08:43 UTC 


\title{
Measuring the size of the shadow economy using a dynamic general equilibrium model with trends*
}

\author{
Mario Solis-Garcia ${ }^{\dagger}$ \\ Macalester College
}

\author{
Yingtong $\mathrm{Xie}^{\ddagger}$ \\ University of Wisconsin-Madison
}

May 5, 2017

\begin{abstract}
We propose a methodology for measuring the size and properties of the shadow economy. We use a two-sector dynamic deterministic general equilibrium model with four different trends: hours worked, investment-specific productivity, formal productivity, and shadow productivity. We find that the shadow productivity trend is endogenous, in the sense that it is an exact function of model parameters and the other three trends. We also document that, in order to be consistent with observed (real-world) trend growths, the shadow sector needs to exhibit increasing returns to scale, which is contrary to the standard procedure of imposing decreasing returns to this sector. We apply our methodology to a set of seven Latin American and Asian countries and document several empirical regularities that emerge from our analysis, the most important one being that the volatility of shadow sector output is considerably larger than the one in formal sector output.
\end{abstract}

JEL codes: E26, E32, O17.

Keywords: shadow economy, business cycles, DSGE models.

* We thank Jesús Rodríguez-López and Gary Krueger for valuable comments on earlier versions of the paper, as well as seminar participants at the 2016 Workshop on Macroeconomics Research at Liberal Arts Colleges, the 2016 Southern Economic Association meetings, and the University of Minnesota's Freeman Center for International Economic Policy's Global Policy Seminar. Finally, we gratefully acknowledge support from the Allianz Life Insurance Company Student Summer Research Fund.

$\dagger$ Corresponding author. E-mail: msolisga@macalester.edu.

$\ddagger$ E-mail: yingtong.xie@wisc.edu. 


\section{Introduction}

This paper proposes a methodology for measuring the size and properties of the shadow economy based on a dynamic deterministic general equilibrium model. While other authors have used DGE models as well, nearly all of them disregard the trend component found in most economic time series. In our methodology, we exploit the dynamics of observed trends to account for both the size and the cyclicality of the shadow economy, as they impose a set of equilibrium restrictions over the growth rates of the model variables (including shadow sector output). Ignoring these restrictions - or imposing ad-hoc growth rates to quantify the dynamics of the shadow economy—may produce biased results. ${ }^{1}$

We show that explicitly incorporating the trends of the model variables into the analysis offers a very different picture of the shadow economy relative to earlier studies. We start from a twosector model where the representative household has access to formal and shadow technologies; the former uses physical capital and labor for production while the latter is labor-exclusive. We go one step beyond by including stochastic trends on formal productivity, shadow productivity, investment-specific technological progress, and hours worked. ${ }^{2}$

While the first three trends are considered standard in the literature, the last one deserves some justification. Our main motivation is the fact that the number of hours worked (per capita), especially in developing countries, has been increasing steadily over time. As an example, consider the evolution of hours worked per capita for Brazil and Mexico (normalized to 100 in 1980), as shown in Figure 1 below:

\footnotetext{
${ }^{1}$ As an example, Elgin and Öztunalı (2012) calculate a biased estimate of the size of the shadow economy because the imputed growth rates of the shadow economy do not follow equilibrium conditions. In particular, they assume that the growth rate of the shadow sector productivity is the average of the growth rates of the formal sector productivity and the capital stock. See Remark 4.2 for a discussion of this potential bias.

2 Our modeling strategy and choice of trends is inspired by the work of Lafourcade and de Wind (2012).
} 


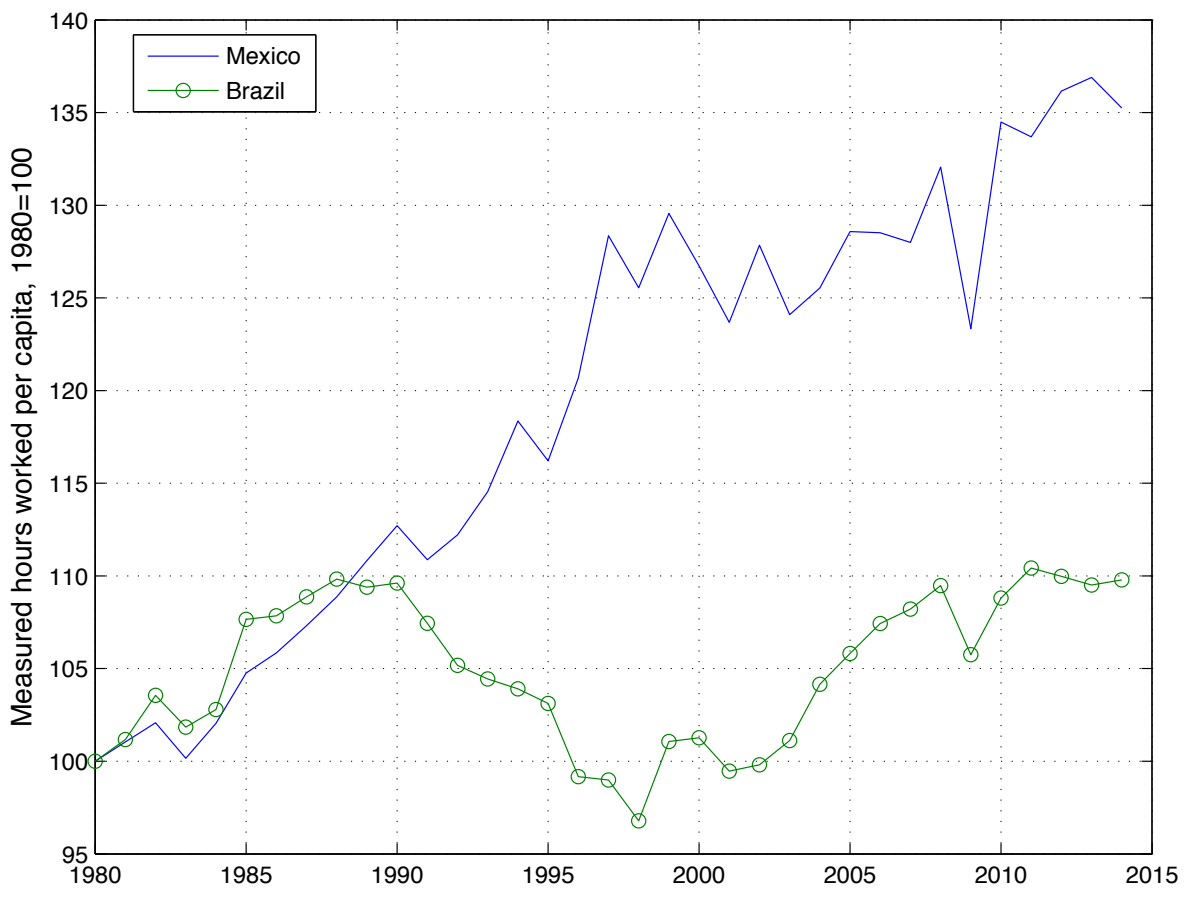

Figure 1: Hours worked per capita, Brazil and Mexico, 1980-2014.

The index for Brazil hovers around a mean of 105, yet the one for Mexico has been increasing throughout the sample. This growth can be accounted for by changes in the labor market (e.g., female workers entering the labor force) or the recurrent economic crises that have forced workers to take additional jobs or pushed additional household members to enter the labor force (this is commonplace in developing economies, where a social safety net is close to nonexistent). While our methodology remains silent about the underlying cause of this steady increase, we believe that omitting this trend can overlook relevant dynamics of the formal and shadow sectors.

We summarize our findings as follows. First, the model-imposed restrictions require the shadow output trend to be an endogenous function of the exogenous trends (formal output, investment-specific technological progress, and hours); hence, we can use real-world data to back out the dynamics of the shadow sector. Second, we show that in order to be consistent with the remaining trends, the shadow production technology necessarily exhibits increasing returns to scale. Third, we apply our methodology to a set of Latin American and Asian countries and find 
that the evolution of the shadow sector responds to aggregate shocks in a way that is consistent with the economic history of each country. Finally, we document that the volatility of shadow sector output is considerably larger than the one in formal sector output.

The rest of the paper is structured as follows. Section 2 presents a brief survey of the earlier literature on measuring the size of the shadow economy. Section 3 presents the model economy in detail while Section 4 shows how we deal with the model's stochastic trends and lists the main results that allow us to derive the size of the shadow economy. Section 6 provides the main time series and their statistical properties, while Section 7 concludes.

\section{Characterizing and measuring the shadow economy}

The terminology regarding the shadow economy is often loosely used and exchanged for other concepts that are not necessarily equivalent. In this section, we aim to provide a clear map between the currently accepted notions and our working definition of the shadow economy. We also present and discuss how other researchers have developed their estimates for the size of the shadow economy. ${ }^{3}$

\subsection{Defining the shadow economy}

The Organisation for Economic Co-operation and Development (see OECD 2002) uses the term "non-observed economy" as a catch-all concept that stands in for the following categories of production:

1. Underground production: goods and services that are kept off the market in order to avoid taxes or regulations.

2. Illegal production: goods and services that are prohibited by law.

\footnotetext{
3 The material below borrows heavily from Solis-Garcia and Xie (2016a).
} 
3. Informal sector production: goods and services that are produced by firms that are either unregistered or below a threshold of employment.

4. Production of households for own-final use: goods and services produced within the household for self-consumption.

5. Statistical underground: goods and services that should be accounted for but are not because they are overlooked by statistical agencies.

In this paper, our concept of the shadow economy includes both the underground and informal sector production; the remaining three categories are left out of our unit of analysis. (For example, Schneider, Buehn, and Montenegro 2010 rule out illegal production. The statistical underground is hard to quantify and the production of households for own-final use includes a different set of productive activities that are not meant to be traded in the market.)

\subsection{Measurement of the shadow economy: early approaches}

Measuring the size of the shadow economy is not easy. In their survey paper, Schneider and Enste (2000) discuss three methodologies to calculate this value; here we examine them briefly and refer to their paper for additional details.

Schneider and Enste use the term "direct approaches" to refer to (direct) surveys and samples that attempt to quantify the number of productive entities that belong in the shadow economy. However, these methods often provide biased estimates as respondents may lie about their formal/shadow status. Also, the cost of implementing surveys of this kind makes it unlikely to be used in a frequent basis and, therefore, to provide a consistent time series over a long period of time.

The second methodology relies on macroeconomic indicators to infer the size of the shadow 
economy over time-Schneider and Enste denote this broadly as "indirect approaches." First, they consider the discrepancy between the expenditure and income measures in national accounts: since these (by construction) need to be the same, any difference between expenditures and income values of GDP could provide a measure of the shadow economy. Second, they look at the discrepancy between the official and actual labor force: a fall in the participation rate could point to an active shadow economy. The transactions approach conjectures a stable relation between the total volume of transactions and GDP and uses this as a base to quantify the size of the shadow economy. The currency demand approach assumes that all of the shadow economy transaction are carried out in cash, so that an increase in shadow economy activity will result in an increase in the demand for currency. Finally, the physical input method uses the (near unit) elasticity between electricity and GDP as well as the growth of electricity consumption to infer the growth of the shadow economy.

In the "model approach," the researcher uses structural econometric models to back out the size of the shadow economy. The main idea behind this class of models is that the shadow economy does not have a single cause and does not exhibit a single effect when it operates over time. Hence, a structural econometric framework can be used to infer the size of the shadow sector by looking (simultaneously) both at the hypothesized causes of the shadow economy (e.g., tax rates and regulation) as well as the hypothesized effects (e.g., participation rates and currency demand). This methodology is called the multiple-indicators multiple-causes model (MIMIC) and is the technique used by Schneider et al. (2010) to derive the values that we use in this study. For comparison purposes, we include their estimates when assessing the performance of our model. 


\subsection{Measurement of the shadow economy: general equilibrium}

Besides the work of Schneider et al. (2010) mentioned above, we want to point to two contributions that are related to this paper as they make full use of DSGE models. ${ }^{4}$

We first consider the work of Elgin and Öztunalı (2012). They use a DSGE model (based on the work of Ihrig and Moe 2004) to build time series of the size of the shadow economy for a large panel -60 years and over 150 countries, compared to the 9 observations found in Schneider et al. While their methodology uses dynamic methods (as we do), we find that their estimates are potentially biased since the growth rates of the shadow economy are arbitrarily imposed and do not follow the equilibrium conditions of the model (see Remark 4.2). Nonetheless, we also include their estimates when assessing the performance of our model.

Orsi, Raggi, and Turino (2014) is perhaps the closest work to ours in terms of modeling approach. They build a two-sector DSGE model to infer the size of the shadow economy as a latent variable, while taking trend growth into account. That said, our paper is substantially different from theirs given that they use a (deterministic) labor-augmenting technological progress trend. ${ }^{5}$ While they use Bayesian methods to estimate their model parameters and derive the size and properties of the shadow economy from the model's own forecasts, the nature of their model (and their focus on the Italian case only) suggests that these are fairly different approaches to measuring the shadow economy.

\footnotetext{
${ }^{4}$ Even though it is a full-fledged DSGE model, we don't include the work of Gomis-Porqueras, Peralta-Alva, and Waller (2014) as it is built on top of a monetary search model; in this sense, we believe it is closer in spirit to the currency demand approach than to the modeling strategy we follow below.

${ }^{5}$ In this case, all the endogenous variables in the model grow at the same rate, which at least for the case of the United States has not been supported by the data; see Whelan (2003).
} 


\section{Model}

The model consists of a representative household-producer and a government; both agents are described below. In what follows, uppercase letters denote trending variables while lowercase letters denote stationary variables.

\subsection{Household-producer}

The household-producer chooses sequences of consumption $C_{t}$, hours worked $N_{t}$, and investment $X_{t}$ to maximize

$$
\sum_{t=0}^{\infty} \beta^{t}\left(\frac{C_{t}^{1-\sigma}}{1-\sigma}-\frac{\phi \Gamma_{H t} N_{t}^{1+\chi}}{1+\chi}\right)
$$

where $\beta \in(0,1)$ is the discount factor, $\sigma \in \mathbb{R}$ is the intertemporal elasticity of substitution, $\phi>0$ is a parameter quantifying the disutility of labor, $\chi \geq 0$ is the inverse of the Frisch elasticity of labor supply, and $\Gamma_{H t}$ is a permanent shock that affects the household's choice of hours. Maximization is subject to a set of constraints: first, a law of motion for capital

$$
K_{t+1}=(1-\delta) K_{t}+X_{t}
$$

where $\delta \in(0,1)$ is the depreciation rate and $K_{t}$ denotes the stock of physical capital. Second, a household time constraint

$$
N_{t}=N_{F t}+N_{S t}
$$

where $N_{F t}$ denotes hours worked in the formal sector and $N_{S t}$ does so for the shadow sector. Finally, a budget constraint

$$
C_{t}+\Gamma_{A t} X_{t}=\left(1-\tau_{t}\right) K_{t}^{\alpha}\left(\Gamma_{F t} N_{F t}\right)^{1-\alpha}+\left(\Gamma_{S t} N_{S t}\right)^{\eta},
$$


where $\alpha \in(0,1)$ is the capital income share in formal output and $\eta>0$ is the labor share in shadow output, $\Gamma_{A t}$ is a permanent shock to the production of investment goods, and $\tau_{t} \in(0,1)$ is a tax on formal sector output $K_{t}^{\alpha}\left(\Gamma_{F t} N_{F t}\right)^{1-\alpha}$. We let $\left(\Gamma_{S t} N_{S t}\right)^{\eta}$ denote shadow sector output (we assume that the government cannot tax shadow sector output). Formal and shadow production technologies are subject to the permanent productivity shocks $\Gamma_{F t}$ and $\Gamma_{S t}$.

\subsection{Government}

We include a government sector to account for the effect that tax rates have over the size of the shadow sector (e.g., Ihrig and Moe 2004). We assume that the government uses tax revenue to fund a stream of non-productive expenditure $G_{t}$ and that it satisfies its period-by-period budget constraint

$$
G_{t}=\tau_{t} K_{t}^{\alpha}\left(\Gamma_{F t} N_{F t}\right)^{1-\alpha}
$$

Given equation (3.4), government expenditure is an endogenous variable in our model.

\subsection{Exogenous processes}

The set of permanent exogenous shocks is given by $\Gamma_{H t}, \Gamma_{A t}$, and $\Gamma_{F t}$. (Proposition 4.1 shows that $\Gamma_{S t}$ is an endogenous variable.) In particular, for $i=\{H, A, F, S\}$,

$$
g_{i t}=\frac{\Gamma_{i t}}{\Gamma_{i, t-1}}
$$

where $g_{i t}$ denotes the (gross) growth rate of variable $i .^{6}$

\footnotetext{
${ }^{6}$ Conversely, $\Gamma_{i t}=\prod_{s=1}^{t} g_{i s}$.
} 


\subsection{Equilibrium}

The equilibrium conditions of the model are given $\mathrm{by}^{7}$

$$
\begin{aligned}
C_{t}+\Gamma_{A t} X_{t}+G_{t} & =K_{t}^{\alpha}\left(\Gamma_{F t} N_{F t}\right)^{1-\alpha}+\left(\Gamma_{S t} N_{S t}\right)^{\eta} \\
K_{t+1} & =(1-\delta) K_{t}+X_{t} \\
N_{t} & =N_{F t}+N_{S t} \\
\Gamma_{A t} C_{t}^{-\sigma} & =\alpha \beta C_{t+1}^{-\sigma}\left(1-\tau_{t+1}\right) K_{t+1}^{\alpha-1}\left(\Gamma_{F, t+1} N_{F, t+1}\right)^{1-\alpha}+\beta(1-\delta) \Gamma_{A, t+1} C_{t+1}^{-\sigma} \\
\phi \Gamma_{H t} N_{t}^{\chi} & =(1-\alpha) C_{t}^{-\sigma}\left(1-\tau_{t}\right) K_{t}^{\alpha} \Gamma_{F t}^{1-\alpha} N_{F t}^{-\alpha} \\
\eta \Gamma_{S t}^{\eta} N_{S t}^{\eta-1} & =(1-\alpha)\left(1-\tau_{t}\right) K_{t}^{\alpha} \Gamma_{F t}^{1-\alpha} N_{F t}^{-\alpha} \\
G_{t} & =\tau_{t} K_{t}^{\alpha}\left(\Gamma_{F t} N_{F t}\right)^{1-\alpha} .
\end{aligned}
$$

We add expressions for formal, shadow, and total output

$$
\begin{aligned}
Y_{F t} & =K_{t}^{\alpha}\left(\Gamma_{F t} N_{F t}\right)^{1-\alpha} \\
Y_{S t} & =\left(\Gamma_{S t} N_{S t}\right)^{\eta} \\
Y_{t} & =Y_{F t}+Y_{S t},
\end{aligned}
$$

and derive an expression for the decentralized price of investment goods; from equation (3.8),

$$
P_{X t}=\Gamma_{A t} .
$$

\footnotetext{
${ }^{7}$ See the technical appendix for the derivation of these results.
} 


\section{Dealing with the trends}

The model includes trends in the household's choice of hours worked $\left(\Gamma_{t}^{H}\right)$, the production of investment goods $\left(\Gamma_{t}^{A}\right)$, and formal and shadow technology productivity $\left(\Gamma_{t}^{F}\right.$ and $\left.\Gamma_{t}^{S}\right)$. Hence, we

need to find the relevant growth rates (as a function of the exogenous rates $\gamma_{t}^{H}, \gamma_{t}^{A}$, and $\gamma_{t}^{F}$ ) for each of the model's variables.

\subsection{Deterministic growth rates}

We use (3.5)-(3.15) to calculate the balanced growth path growth rates imposed by the model. (We will use "equilibrium" and "balanced growth path" interchangeably. Also, growth rates without a time subscript indicate equilibrium values.) From the aggregate resource constraint, law of motion for capital, and household time constraint we get

$$
\begin{gathered}
g_{Y}=g_{C}=g_{A} g_{X}=g_{G} \\
g_{K}=g_{X} \\
g_{N}=g_{N_{F}}=g_{N_{S}} .
\end{gathered}
$$

The inter- and intratemporal conditions require

$$
\begin{aligned}
g_{A} & =g_{Y_{F}} g_{K}^{-1} \\
g_{H} g_{N}^{\chi} & =g_{C}^{-\sigma} g_{Y_{F}} g_{N_{F}}^{-1} \\
g Y_{S} g_{N_{S}}^{-1} & =g_{Y_{F}} g_{N_{F}}^{-1},
\end{aligned}
$$


where we set $g_{\tau}=1$ in (4.4) since we assume tax rates are stationary. From the production side

$$
\begin{aligned}
& g_{Y_{F}}=g_{K}^{\alpha}\left(g_{F} g_{N_{F}}\right)^{1-\alpha} \\
& g_{Y_{S}}=\left(g_{S} g_{N_{S}}\right)^{\eta}
\end{aligned}
$$

and the final restrictions are

$$
\begin{gathered}
g_{Y}=g_{Y_{F}}=g Y_{S} \\
g_{P_{X}}=g_{A} .
\end{gathered}
$$

We now present the following result (all proofs are contained in Appendix B):

Proposition 4.1. The equilibrium growth rates of the capital stock, $g_{K}$; (formal and shadow) hours worked, $g_{N}$; (formal, shadow, and total) output, $g_{Y}$; and the permanent shock to the shadow production function, $g_{S}$, are given by

$$
\begin{aligned}
& g_{K}=g_{H}^{-1 /(\sigma+\chi)} g_{A}^{-[\alpha(1-\sigma)+\sigma+\chi] /[(1-\alpha)(\sigma+\chi)]} g_{F}^{(1+\chi) /(\sigma+\chi)} \\
& g_{N}=g_{H}^{-1 /(\sigma+\chi)} g_{A}^{-\alpha(1-\sigma) /[(1-\alpha)(\sigma+\chi)]} g_{F}^{(1-\sigma) /(\sigma+\chi)} \\
& g_{Y}=g_{H}^{-1 /(\sigma+\chi)} g_{A}^{-\alpha(1+\chi) /[(1-\alpha)(\sigma+\chi)]} g_{F}^{(1+\chi) /(\sigma+\chi)} \\
& g_{S}=g_{H}^{-(1+\eta) /[(\sigma+\chi) \eta]} g_{A}^{-\alpha[1+\chi+(1-\sigma) \eta] /[(1-\alpha)(\sigma+\chi) \eta]} g_{F}^{[1+\chi+(1-\sigma) \eta] /[(\sigma+\chi) \eta]} .
\end{aligned}
$$

Equation (4.14) is central to our paper: it ties the evolution of the shadow sector to the exogenous growth rates of the model $\left\{g_{H}, g_{A}, g_{F}\right\}$ along the equilibrium path and helps us quantify the size of the shadow economy over time.

Remark 4.2. Equation (4.14) also shows why imposing ad-hoc growth rates for the shadow econ- 
omy can provide biased results. For example, Elgin and Öztunalı (2012) assume that shadow sector productivity grows at the average of the growth rates of the formal sector productivity and the capital stock. From (4.11) and (4.14), it's clear that $\frac{1}{2}\left(g_{K}+g_{F}\right) \neq g_{S}$.

\subsection{Observable rates}

Let $\left\{\hat{g}_{K}, \hat{g}_{N_{F}}, \hat{g}_{Y_{F}}\right\}$ denote the long-run averages of the (observed) growth rates of physical capital, formal hours worked, and formal output. We now show how to link these real-world rates with the exogenous rates $\left\{g_{H}, g_{A}, g_{F}\right\}$.

Proposition 4.3. The map between the exogenous growth rates $\left\{g_{H}, g_{A}, g_{F}\right\}$ and the observed growth rates $\left\{\hat{g}_{K}, \hat{g}_{N_{F}}, \hat{g}_{Y_{F}}\right\}$ is given by:

$$
\begin{aligned}
g_{H} & =\hat{g}_{Y_{F}}^{1-\sigma} \hat{g}_{N_{F}}^{-(1+\chi)} \\
g_{A} & =\hat{g}_{Y_{F}} \hat{g}_{K}^{-1} \\
g_{F} & =\left(\frac{\hat{g}_{Y_{F}}}{\hat{g}_{K}^{\alpha} \hat{g}_{N_{F}}^{1-\alpha}}\right)^{1 /(1-\alpha)} .
\end{aligned}
$$

\section{Parametrization}

We set $\alpha=1 / 3, \sigma=1$, and $\chi=1 ;{ }^{8}$ we also need the following assumption:

Assumption 5.1. The observed (real-world) value of real GDP corresponds to formal output $Y_{F t}$.

We take Assumption 5.1 as given and calibrate all of our parameters accordingly. ${ }^{9}$ To obtain the value of the shadow sector labor input parameter $\eta$, we first take the shadow-formal output ratio from Schneider et al. (2010) for a base year $t_{0}$; call this value $Y_{[S / F], t_{0}}$.

\footnotetext{
${ }^{8}$ See the technical appendix (Solis-Garcia and Xie 2016b) where we perform a sensitivity analysis over $\{\sigma, \chi\}$.

${ }^{9}$ Fernández and Meza (2015) also make this assumption in their study of the Mexican shadow employment.
} 
Remark 5.2 (Relevance of the shadow-formal output ratio in the base year). We are aware of the criticisms that Gyomai and van de Ven (2014) make over the estimates of Schneider et al. (2010); we decide to use the values calculated by Schneider et al. for three reasons. First, they are among the most widely used estimates of the size of the shadow economy so it's easy to compare our results to theirs. Second, our methodology only requires the value of the shadow-formal output ratio for a base year; this sets the level of the ratio but the dynamics are not connected to this particular number. Finally, changing the value of the base year to any other value is straightforward.

By construction,

$$
Y_{[S / F], t_{0}}=\frac{Y_{S, t_{0}}}{Y_{F, t_{0}}}
$$

Given data for formal output, shadow output for $t_{0}$ equals

$$
Y_{S, t_{0}}=Y_{[S / F], t_{0}} Y_{F, t_{0}}
$$

Second, we use (5.1) again but now substitute the definition of $Y_{S, t_{0}}$ in the numerator:

$$
Y_{[S / F], t_{0}}=\frac{\left(\Gamma_{S, t_{0}} N_{S, t_{0}}\right)^{\eta}}{Y_{F, t_{0}}}
$$

Solving for $N_{S, t_{0}}$,

$$
N_{S, t_{0}}=\frac{\left(Y_{[S / F], t_{0}} Y_{F, t_{0}}\right)^{1 / \eta}}{\Gamma_{S, t_{0}}} .
$$

We can deduce the following result from equation (5.3).

Remark 5.3 (Increasing returns to scale in the shadow economy). In equation (5.3), the term inside the parenthesis in the numerator is a fraction of formal output and is significantly larger than unity. In order to obtain reasonable values for $N_{S t}$ it must be the case that $\eta \geq 1$ (other- 
wise shadow labor explodes); hence, in our methodology, the shadow sector necessarily exhibits increasing returns to scale.

Third, we take the intratemporal condition (3.10) and solve for $\eta$ :

$$
\eta=\frac{(1-\alpha)\left(1-\tau_{t_{0}}\right) Y_{F, t_{0}} N_{S, t_{0}}}{N_{F, t_{0}} Y_{S, t_{0}}}
$$

Plugging from (5.2) and (5.3) and simplifying: ${ }^{10}$

$$
\eta=\frac{(1-\alpha)\left(1-\tau_{t_{0}}\right) Y_{F, t_{0}}^{1 / \eta} Y_{[S / F], t_{0}}^{(1-\eta) / \eta}}{N_{F, t_{0}} \Gamma_{S, t_{0}}}
$$

Equation (5.4) is a nonlinear function of $\eta$, the (known) parameter $\alpha$, and real-world values as $\Gamma_{S, t_{0}}$ is itself a function of $\eta$ and observed trend values $\left\{\Gamma_{H, t_{0}}, \Gamma_{A, t_{0}}, \Gamma_{F, t_{0}}\right\}$. We use a fixed point procedure to find the value of $\eta$ such that (5.4) is satisfied. The algorithm behind the procedure is described next.

\section{Algorithm 5.4.}

1. Obtain data for the capital stock, formal hours worked, and formal output $\left\{K_{t}, N_{F t}, Y_{F t}\right\}_{t=1}^{T}$; use these to calculate the long-run growth rate averages $\left\{\hat{g}_{K_{t}}, \hat{g}_{N_{F t}}, \hat{g}_{Y_{F t}}\right\}_{t=1}^{T}$ and the triple $\left\{g_{H t}, g_{A t}, g_{F t}\right\}_{t=1}^{T}$ following (4.15)-(4.17).

2. Pick a base year $t_{0}$ and fix values for $\{\alpha, \sigma, \chi\}$. Pick a value $M \gg 0$ and build a grid with $M$ elements over the interval $\left[\eta_{L}, \eta_{H}\right]$, where $\eta_{L} \geq 1$ (see Remark 5.3); call this set $\mathcal{N}$.

3. For every $\eta_{m} \in \mathcal{N}$,

(a) Calculate $\left\{\Gamma_{S t}\right\}_{t=1}^{T}$ following (4.14); without loss of generality set $\Gamma_{S, t_{0}}=1$.

\footnotetext{
10 From (3.4) and period-by-period government budget balance we get that $\tau_{t_{0}}=G_{t_{0}} /\left[K_{t_{0}}^{\alpha}\left(\Gamma_{F, t_{0}} N_{F, t_{0}}\right)^{1-\alpha}\right]=$ $G_{t_{0}} / Y_{F, t_{0}}$; the last term can be easily backed out from real-world data (recall that $G_{t}$ is endogenous in our model).
} 
(b) Calculate $N_{S, t_{0}}$ following (5.3).

(c) Calculate $\eta$ following (5.4).

4. Find the entry in $\mathcal{N}$ where $\left\|\eta_{m}-\eta\right\|$ is minimized. Set this value as the solution to (5.4) and use it to re-calculate $N_{S, t_{0}}$ following (5.3).

5. Use $\left\{\hat{g}_{N t}\right\}_{t=1}^{T}$ to back out $\left\{\Gamma_{N t}\right\}_{t=1}^{T}$ (see Footnote 6) and use this with $N_{S, t_{0}}$ to back out $\left\{N_{S t}\right\}_{t=1}^{T}$.

6. Use $\left\{\Gamma_{N t}, N_{S t}\right\}_{t=1}^{T}$ and $\eta$ to back out $\left\{Y_{S t}\right\}_{t=0}^{T}$. Use this series along $\left\{Y_{F t}\right\}_{t=1}^{T}$ to calculate $\left\{Y_{[S / F], t}\right\}_{t=1}^{T}$.

\section{Application: size of the shadow economy}

To show the usefulness of our methodology, we first use it to infer the size and dynamics of the shadow sector in Mexico. We also provide some historical context that links the behavior of the time series to real-world events. We then present results for a set of Latin American (Argentina, Brazil, and Venezuela) and Asian countries (Indonesia, Turkey, and Vietnam). We close the section by presenting standard business cycle statistics that compare formal, shadow, and total output.

For comparison purposes, we include the series calculated by Schneider et al. (2010) and Elgin and Öztunalı (2012). In what follows, we set $M=1,000,000$ and pick 2007 as the base year to ease the comparison with the other two series. (See Appendix A for a detailed description of the data used in the analysis.) 


\subsection{Mexico}

Mexico makes an interesting case study for our methodology for several reasons. First, being a developing country, the influence of the shadow economy matters a lot. Second, the recurrent economic crises and the dismal economic growth experienced by the country since 1980 provide a good opportunity to test the predictions of our methodology in the midst of a large economic downturn. The evolution of the shadow-to-formal output ratio is shown in Figure 2.

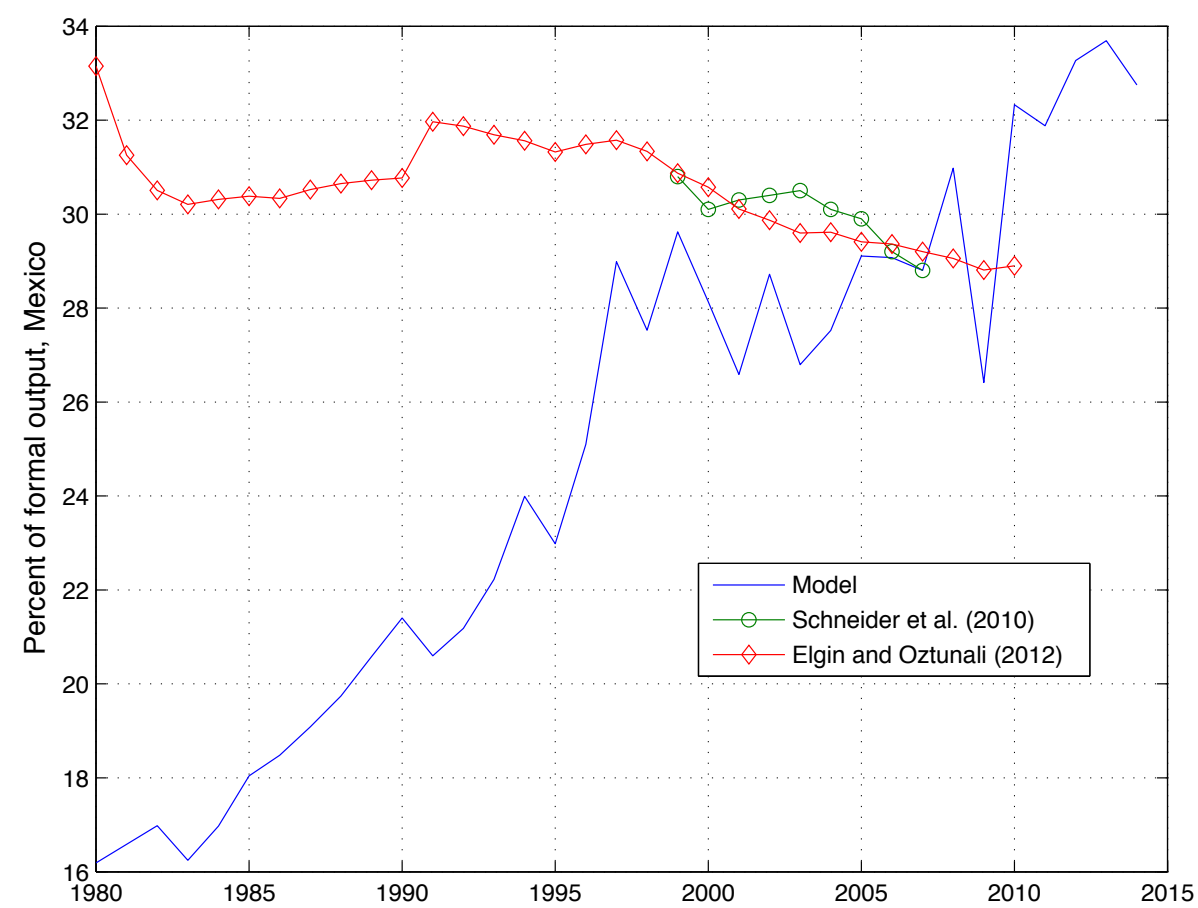

Figure 2: Mexico, shadow-to-formal output ratio, 1980-2014.

Our estimates show that the size of the shadow sector increased throughout Mexico's "lost decade" (1980-1990) and up to the aftermath of the Tequila crisis: between 1980 and 1997, the average shadow sector size climbed from about 16 to $28 \%$. The value remained stable until the Great Recession, when it increased to a peak of $34 \%$. Figure 2 also displays a sizable increase in the shadow sector size after the major economic downturns in Mexico: 1983 (a large depreciation of the Peso and banking sector nationalization; both happened in September 1982), 1995 (the 
Tequila crisis, which started in December 1994), and 2009 (the Great Recession).

Figure 2 also compares our results to the estimates of Schneider et al.: they somewhat agree with our calculations as they present a stationary shadow sector size (though it is slightly above our estimates). Elgin and Öztunalı present a different picture for 1980-1997: their results show a slowly declining shadow sector size that's inconsistent with the economic crises of 1983 and 1995.

Figure 3 aids in understanding the dynamics of the shadow-to-formal output ratio movements by showing the evolution of both shadow and formal outputs; for both series, the value for 1980 is normalized to 100 . Note that the values for formal output come directly from the data while the values for shadow output are generated by our methodology. We find that formal output was 30\% higher in 2014 relative to 1980, while shadow output was about 2.6 times larger. While the shadow output series is considerably more volatile than its formal counterpart, Figure 3 is consistent with a thriving shadow sector and a stagnant formal economy.

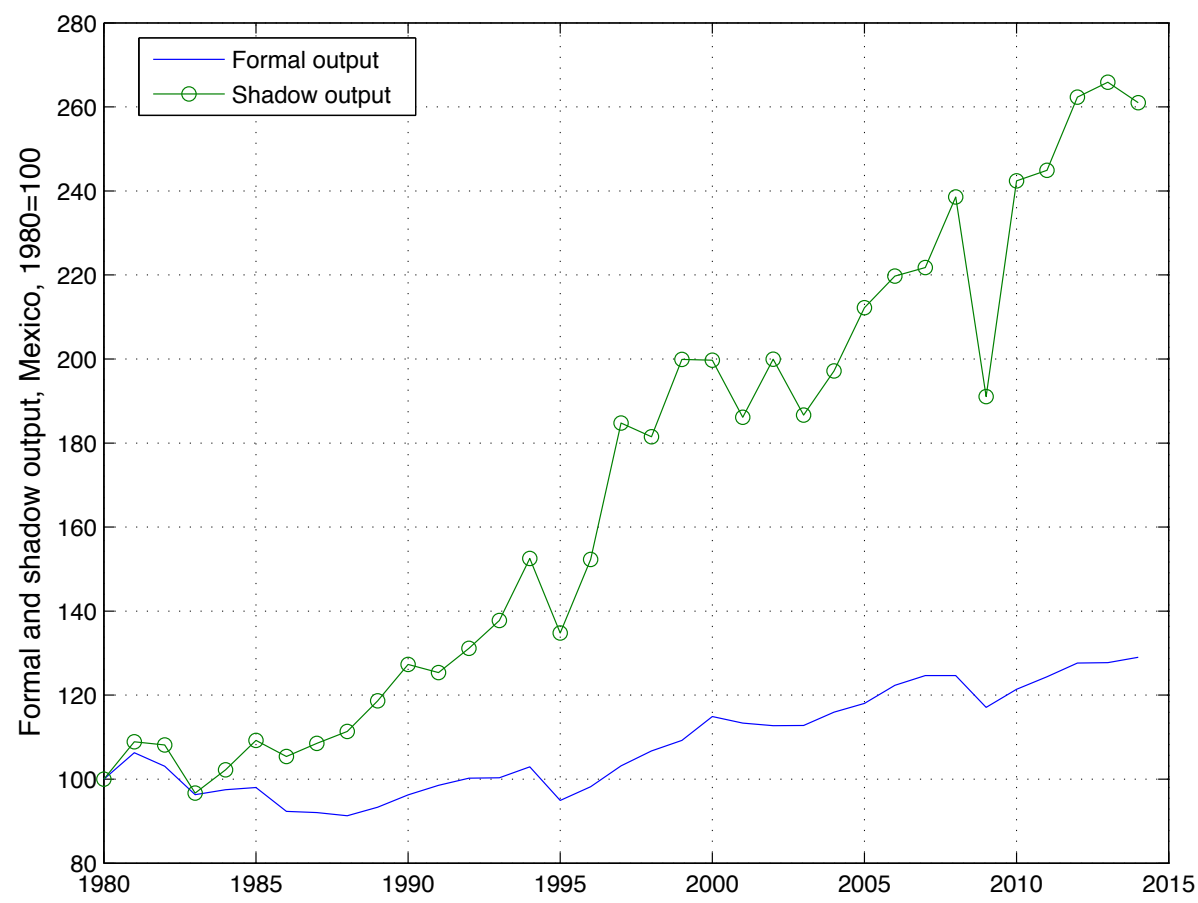

Figure 3: Mexico, formal and shadow output, 1980=100. 


\subsection{Latin American countries: Argentina, Brazil, and Venezuela}

We now show the results of applying our methodology to a set of Latin American countries.

\section{Argentina}

Figure 4 shows the evolution of the Argentinean shadow sector output (as a percentage of formal output) for 1980-2014. Our results suggest that the size of the shadow economy hovered around 17\% from 1980 to 1994, when the influence of the "Tequila crisis" shows up: the size of the shadow economy falls to a bit to $14 \%$ in 1996 and starts increasing up to 1998 . The recession of 1998-2002 has clear effects over the formal and shadow economies. As shown in Figure 4, our methodology implies that the shadow economy falls from 18 to $11 \%$ of formal output in these years.

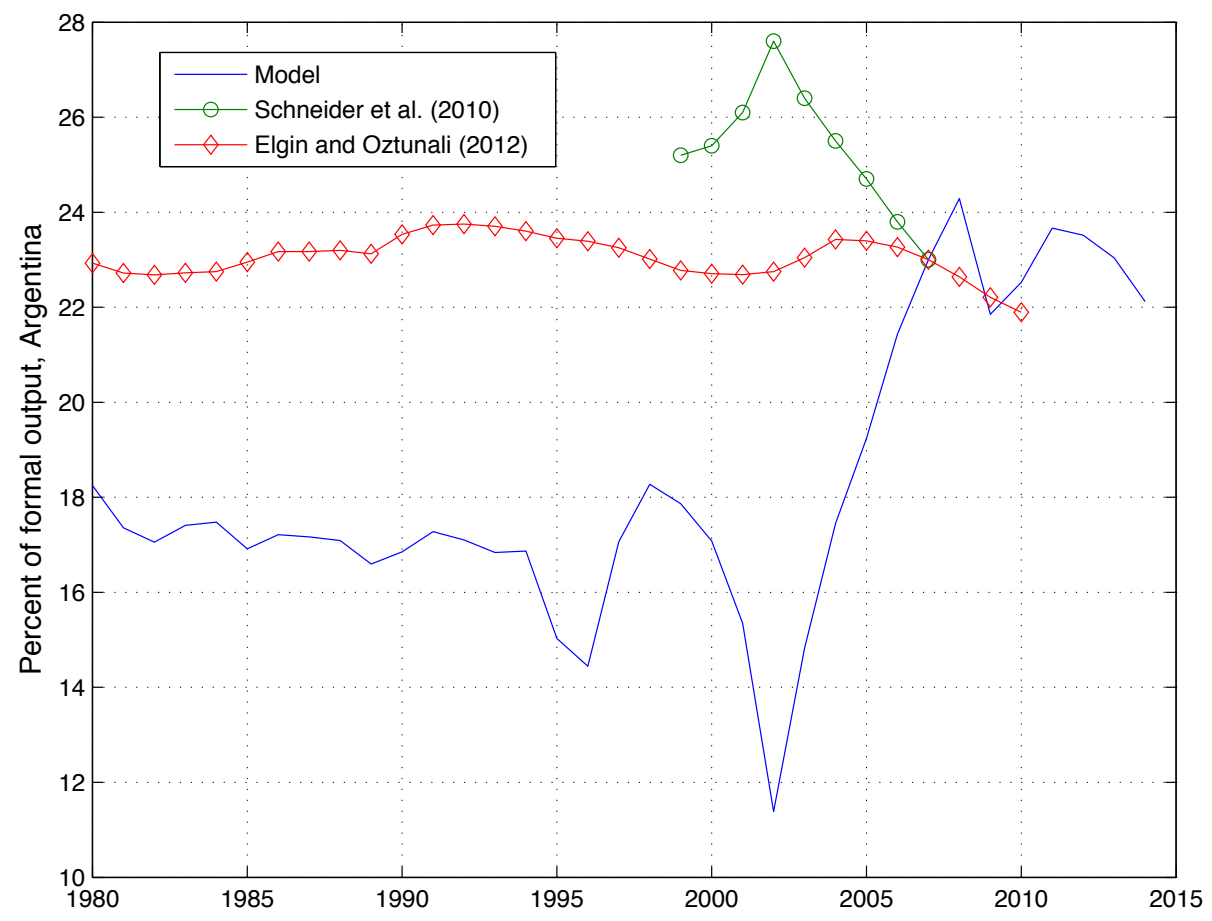

Figure 4: Argentina, shadow-to-formal output ratio, 1980-2014.

The estimates of Schneider et al. are diametrically opposite to our findings: according to their 
calculations, the shadow economy increased in size relative to the formal output between 1998 through 2002, when the ratio begins to drop considerably. Implicitly, this means that shadow output increased far more than formal output, which is hard to believe in a recession of the magnitude experienced in Argentina. On the other hand, the estimates of Elgin and Öztunalı suggest a very stable behavior of the size of the shadow economy throughout the sample. According to their results, the Tequila crisis and the 1998 recession didn't have any effect over the size of the shadow economy; the comment to Schneider et al. applies here as well.

Figure 5 shows the evolution of the formal and shadow output for Argentina. Both formal and shadow output fall but the former does so less than the latter, which accounts for the fall in the relative size of the shadow economy.

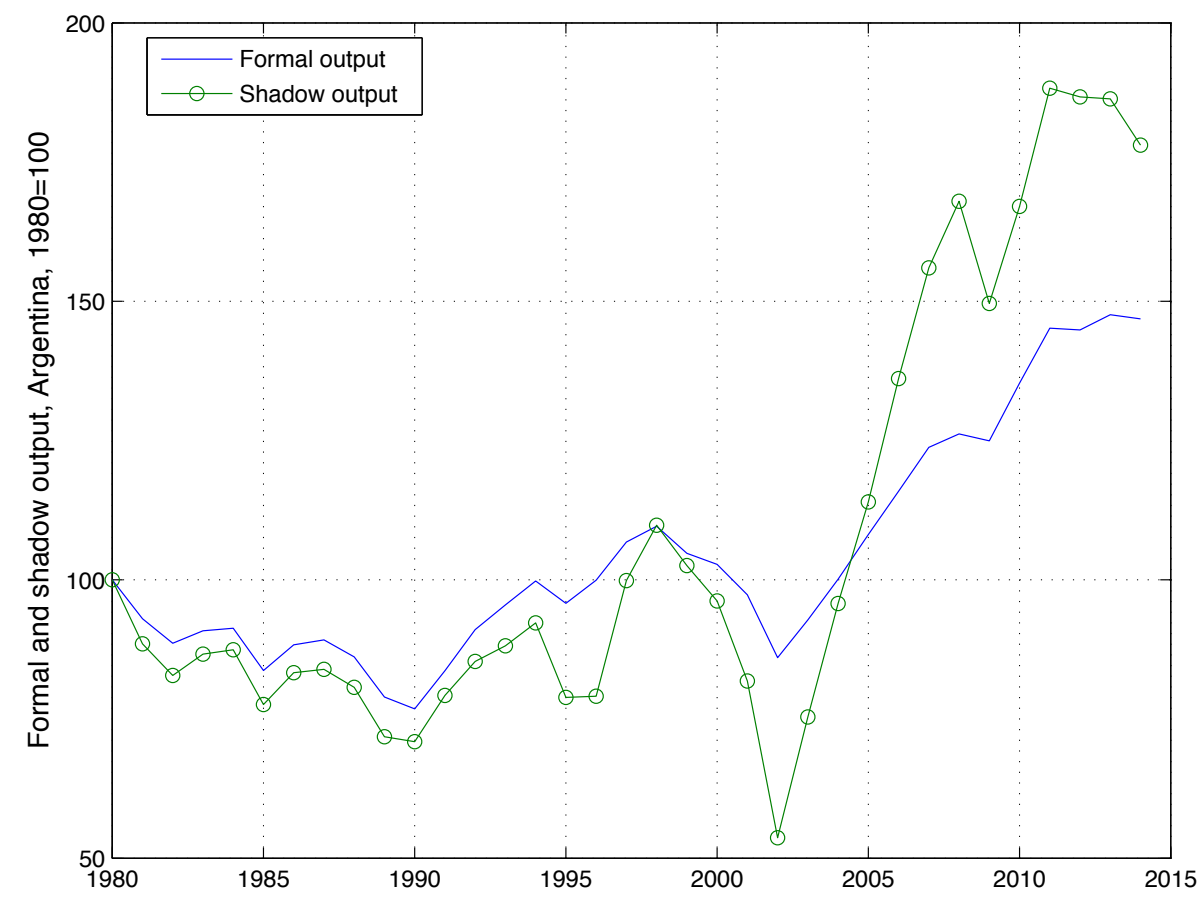

Figure 5: Argentina, formal and shadow output, 1980=100.

The fall in the shadow-to-formal output ratio during the recession of 1998-2002 can be accounted by the sizable contraction of the economy, as shown in Figure 5. Both formal and shadow output decrease: for the formal sector, the fall is about $22 \%$ (relative to 1998); for the 
shadow sector, the fall is nearly 51\%. After the recession the Argentinean economy started to catch up; our results suggest that the formal sector recovered quickly yet the shadow sector did so at a faster rate: in 2008 , the index for shadow sector output was around 170 , while the index for the formal sector was about 125.

\section{Brazil}

Figure 6 shows the evolution of the shadow economy for Brazil, which has experienced large increases and decreases over time. As is well known, Brazil experienced an episode of stagnation in the 1980s: starting from a value of about $31 \%$ in 1980 , the value increased to $38 \%$ by the late 1980s. The ratio then fell by almost 10 percentage points in a short time: by 1998 the shadow economy represented a bit over $28 \%$ of formal output; this seems consistent with the positive effects of the economic reforms of the early 1990s. Since then, there has been an upward trend in the ratio and currently it is back to the same value as in the late 1980 s, around $38 \%$.

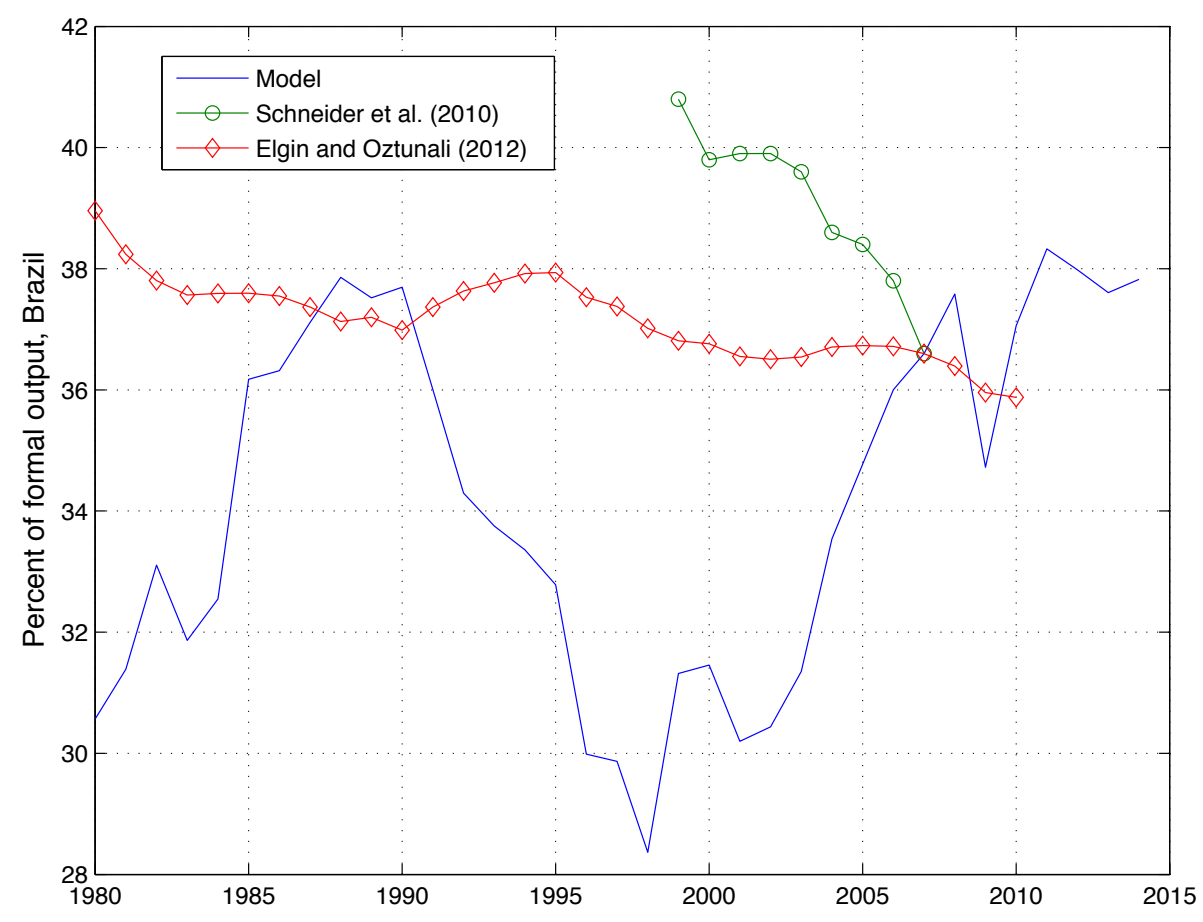

Figure 6: Brazil, shadow-to-formal output ratio, 1980-2014. 
Also from Figure 6, we can see that the results from Schneider et al. are completely different from ours. Their estimates suggest a falling trend from 1999 to 2007, which is opposite to our upward trend. Also, the results from Elgin and Öztunalı do not capture Schneider et al.'s downward trend nor the large movements identified by our methodology.

We can better understand the behavior of the shadow economy by inspecting Figure 7, which shows the evolution of the formal and shadow output for Brazil. Consistent with the stagnation of the 1980s, the shadow economy grows faster than the formal economy in the late 1980s and then begins to shrink, remaining relatively stable until throughout the 1990s. Both the formal and shadow economies have grown since 2001 but the shadow economy has done so at a faster rate.

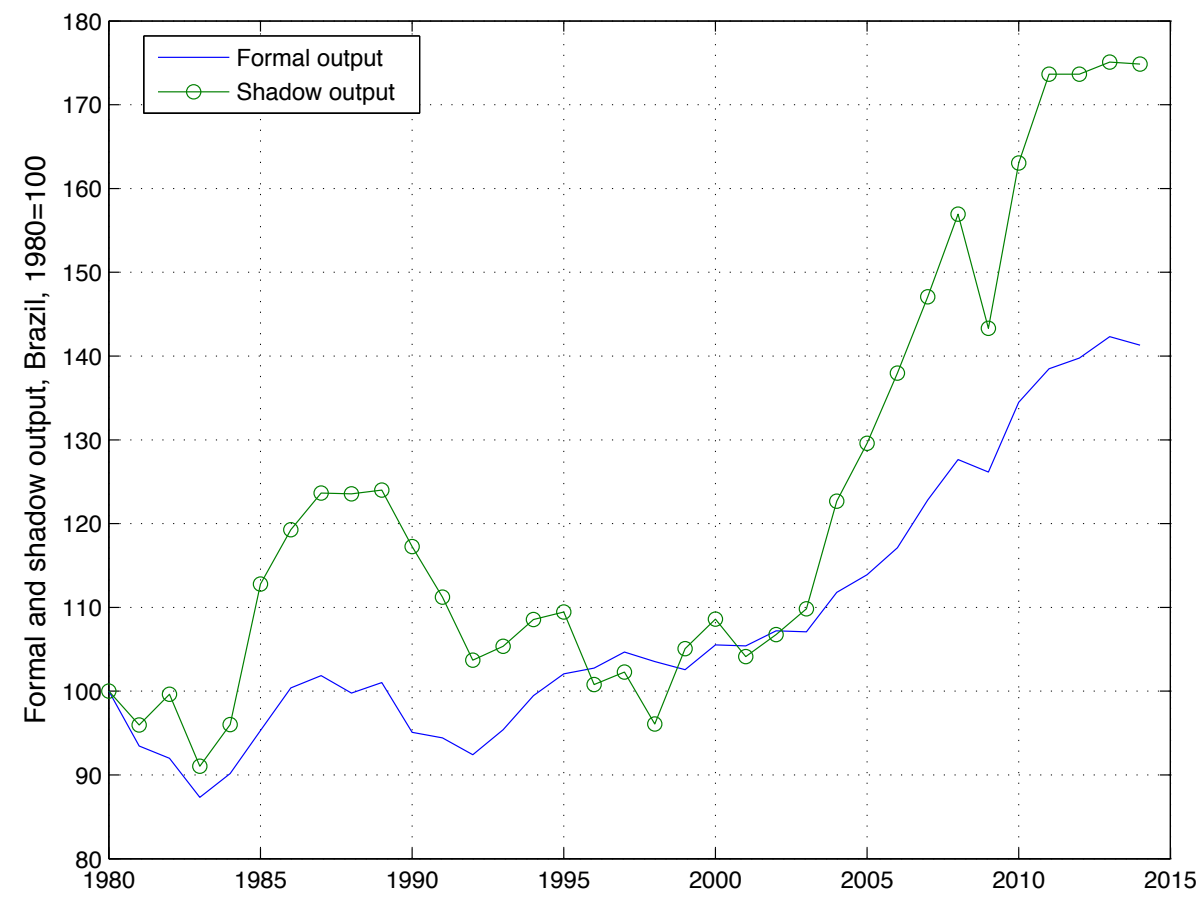

Figure 7: Brazil, formal and shadow output, 1980=100. 


\section{Venezuela}

We now analyze the shadow and formal sector performance in Venezuela. Figure 8 shows the evolution of the shadow economy output relative to formal output. Our estimations suggest that the shadow economy was relatively stable between 1980 and 2000, at around 21\% of formal output. The effect of the recession of 2001 can be seen in the figure, when the size of the shadow sector falls marginally. As the recession ends, the shadow economy takes a larger role in the Venezuelan economy, increasing nearly 15 percentage points in 5 years.

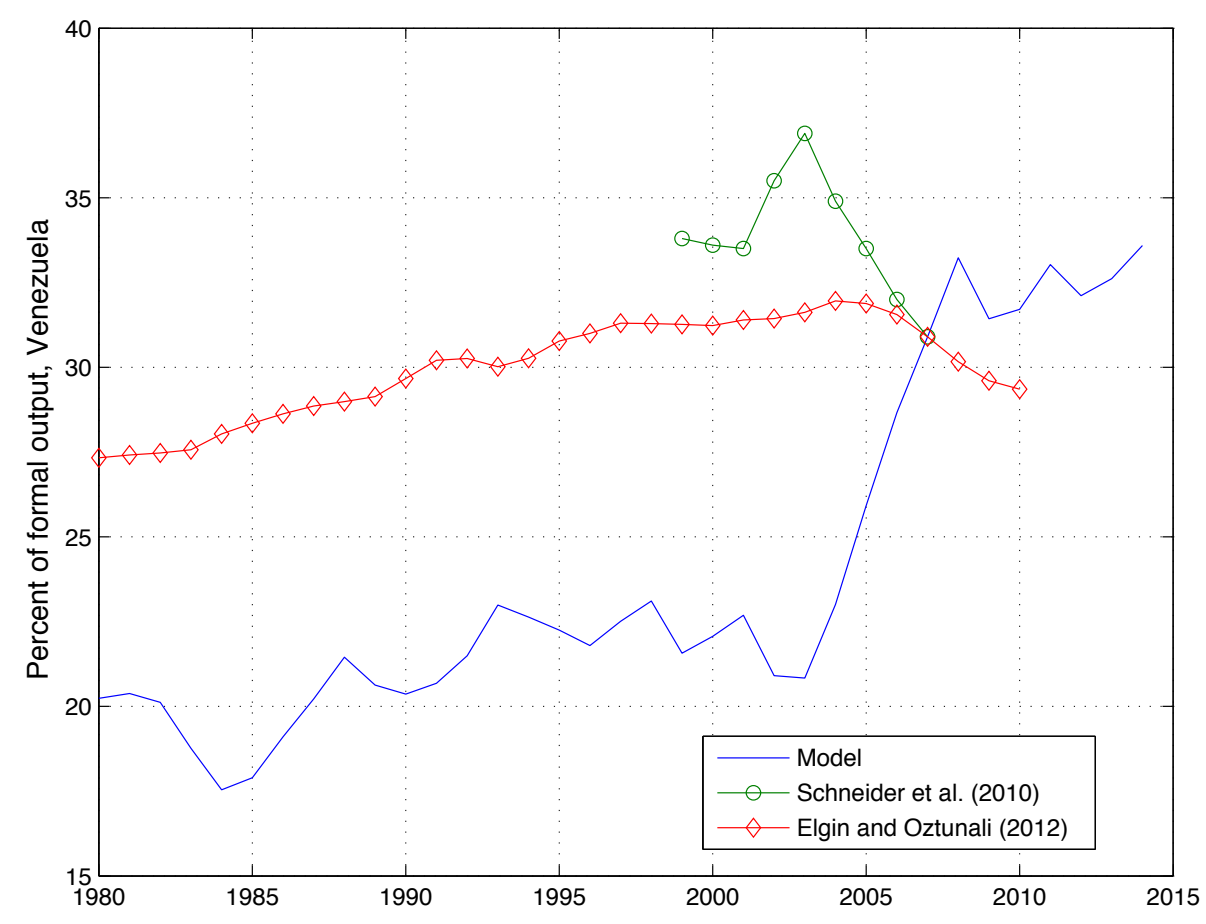

Figure 8: Venezuela, shadow-to-formal output ratio, 1980-2014.

The estimates of Schneider et al. paint a very different picture: the shadow sector increases through 2001-3 and then it starts to fall. On the other hand, Elgin and Öztunalı show a shadow economy that grows steadily between 1980 and 2005 (though at a higher value than our results) and falls between 2005 and 2010. Neither Schneider et al. nor Elgin and Öztunalı capture the sharp increase in shadow sector output (relative to formal output) that our methodology detects 
between 2003 and 2008.

Figure 9 presents formal and shadow output over time. From the figure, we can see that formal output suffered from a series of negative shocks from 1980 to 2001, as it remains below the base value of 100 in 1980. On the other hand, the shadow economy also takes a dive but manages to return to the base year levels by the early 1990s. The figure shows that as the 2001-3 recession ends, both formal and shadow output recover, yet the recovery of the shadow sector is far stronger than the one experienced by the formal sector: by 2008 , the shadow economy is nearly $80 \%$ larger than in 1980, while the formal economy is barely above its 1980 level. This suggests that the economic policies taken by the government have affected the formal economy and that the shadow sector is acting like an escape valve.

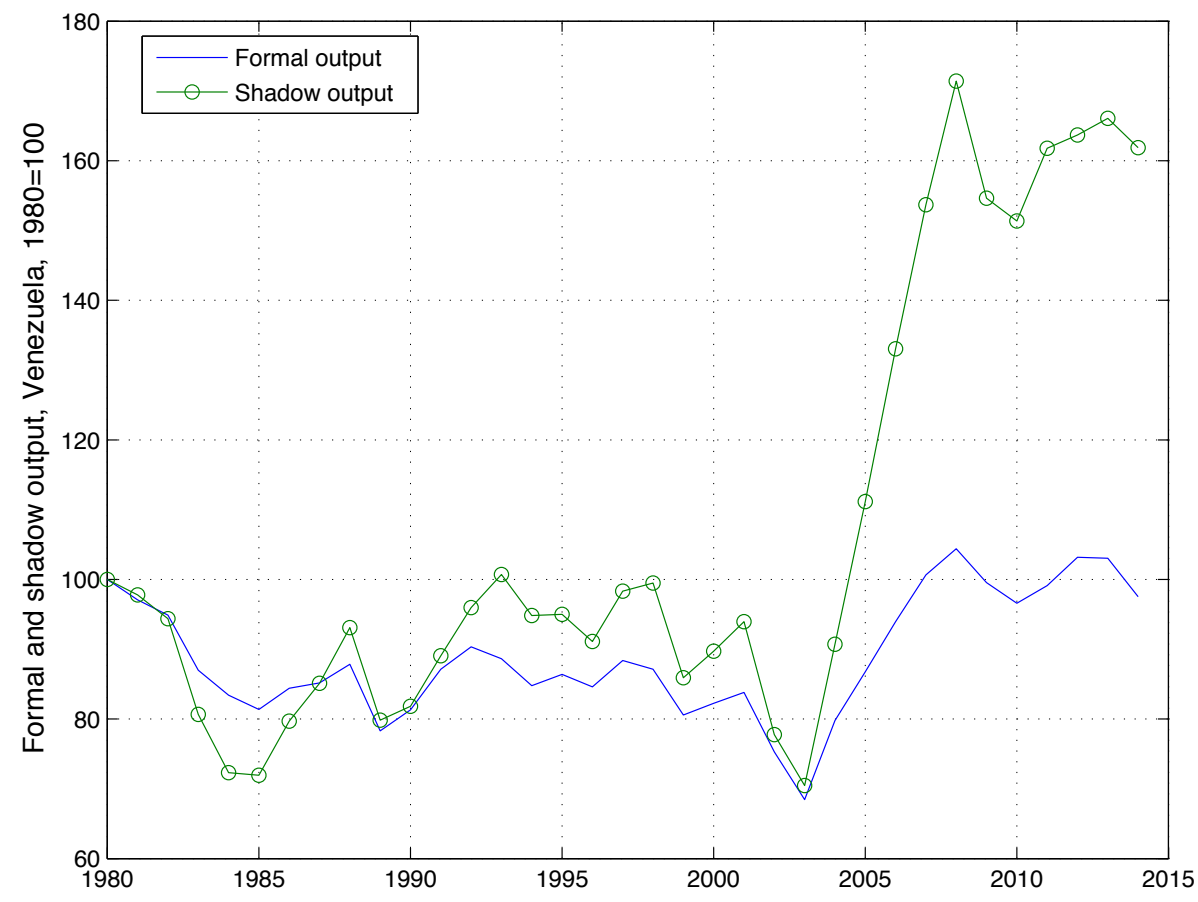

Figure 9: Venezuela, formal and shadow output, 1980=100.

\subsection{Asian countries: Indonesia, Turkey, and Vietnam}

We now show the results of applying our methodology to a set of Asian countries. 


\section{Indonesia}

The evolution of the shadow-to-formal output ratio for Indonesia is shown in Figure 10. After a roughly $50 \%$ increase in the size of the shadow sector-jumping from about 9 to $15 \%-$ throughout the 1980s, the shadow-to-formal output ratio remained relatively constant up to 2006, when it experienced a large increase and a posterior upward trend to date.

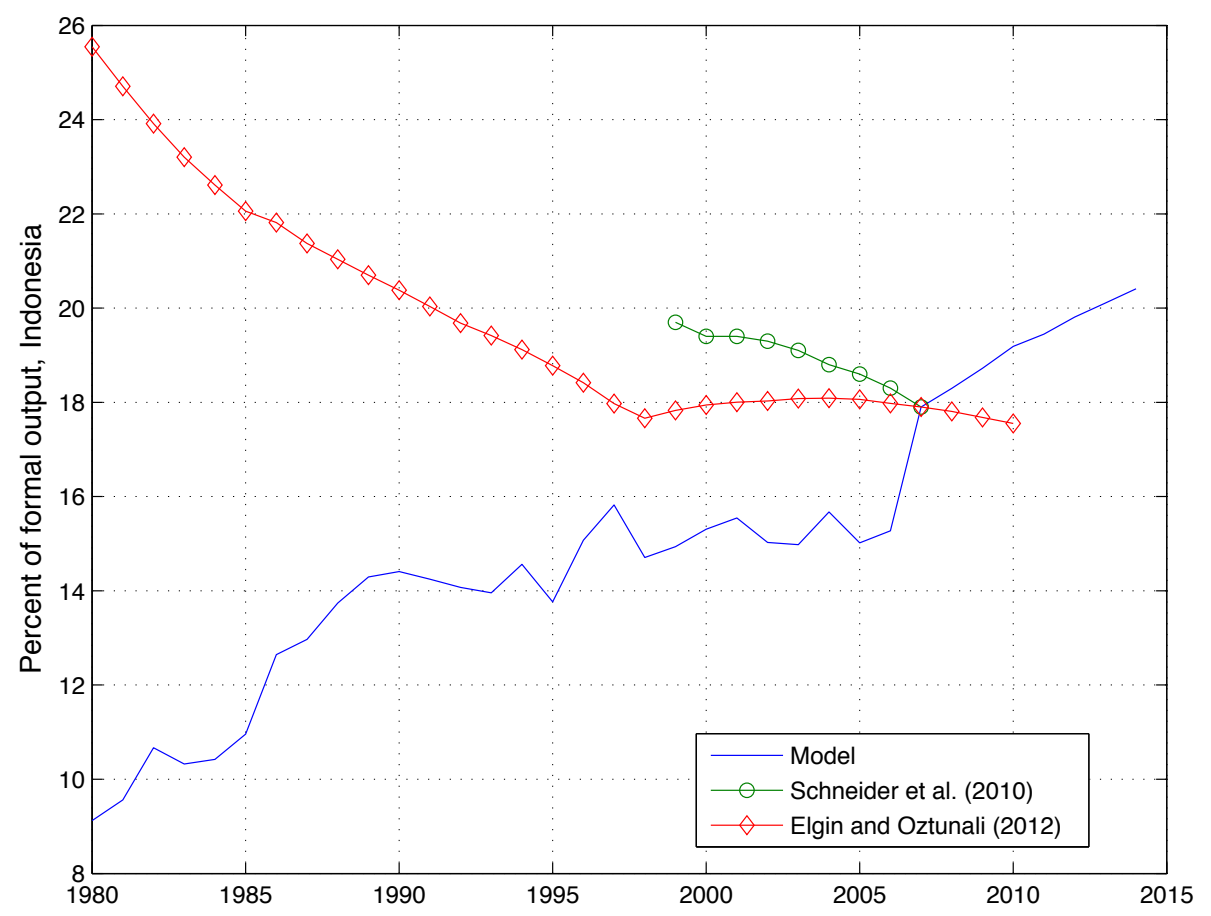

Figure 10: Indonesia, shadow-to-formal output ratio, 1980-2014.

Comparing our results to those of Schneider et al. and Elgin and Öztunalı, we see that their estimates do not coincide with ours. The estimates of Schneider et al. show a downward trend while those of Elgin and Öztunalı present a steep decline up to 1997 and a stable ratio afterwards.

Figure 11 shows the paths of shadow and formal output. We can see that both series have increased dramatically: formal output is more than 3 times its size relative to 1980 while shadow output has grown even more, a near 8-fold increase. From the figure we can see why our methodology predicts a counterintuitive decrease in the shadow-to-formal output ratio during 
the Asian financial crisis of 1997: formal output declined about $15 \%$ but shadow output fell by almost $21 \%$. We can also observe the sizable increase in shadow sector output; we believe that this is a consequence of the crisis experienced by the country in 2004, which perhaps has affected the structure of the economy with a lag.

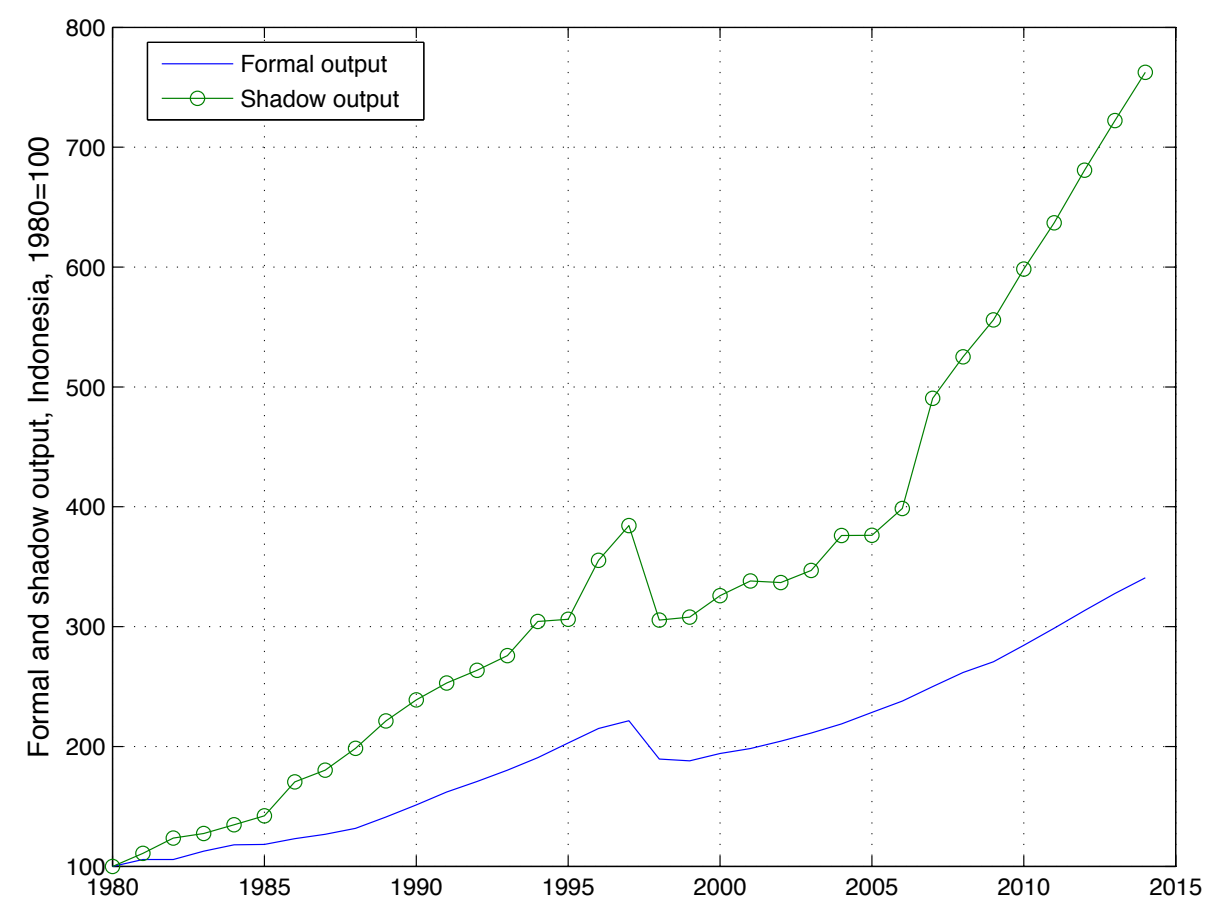

Figure 11: Indonesia, formal and shadow output, 1980=100.

\section{Turkey}

We present the estimates of our methodology for the case of Turkey in Figure 12. Our results show a drastic decrease in the size of the shadow economy (nearly 12 percentage points) from 1980 to 1988; the ratio remains relatively stable at around 30\% and jumps again in 2009 to levels that are comparable to those in the 1980s.

When comparing our results to those of Schneider et al., we see that both series share the downward trend in shadow sector size observed between 1999 and 2007; this trend is also captured by Elgin and Öztunalı yet their results are not consistent (both in trend and magnitude) for 


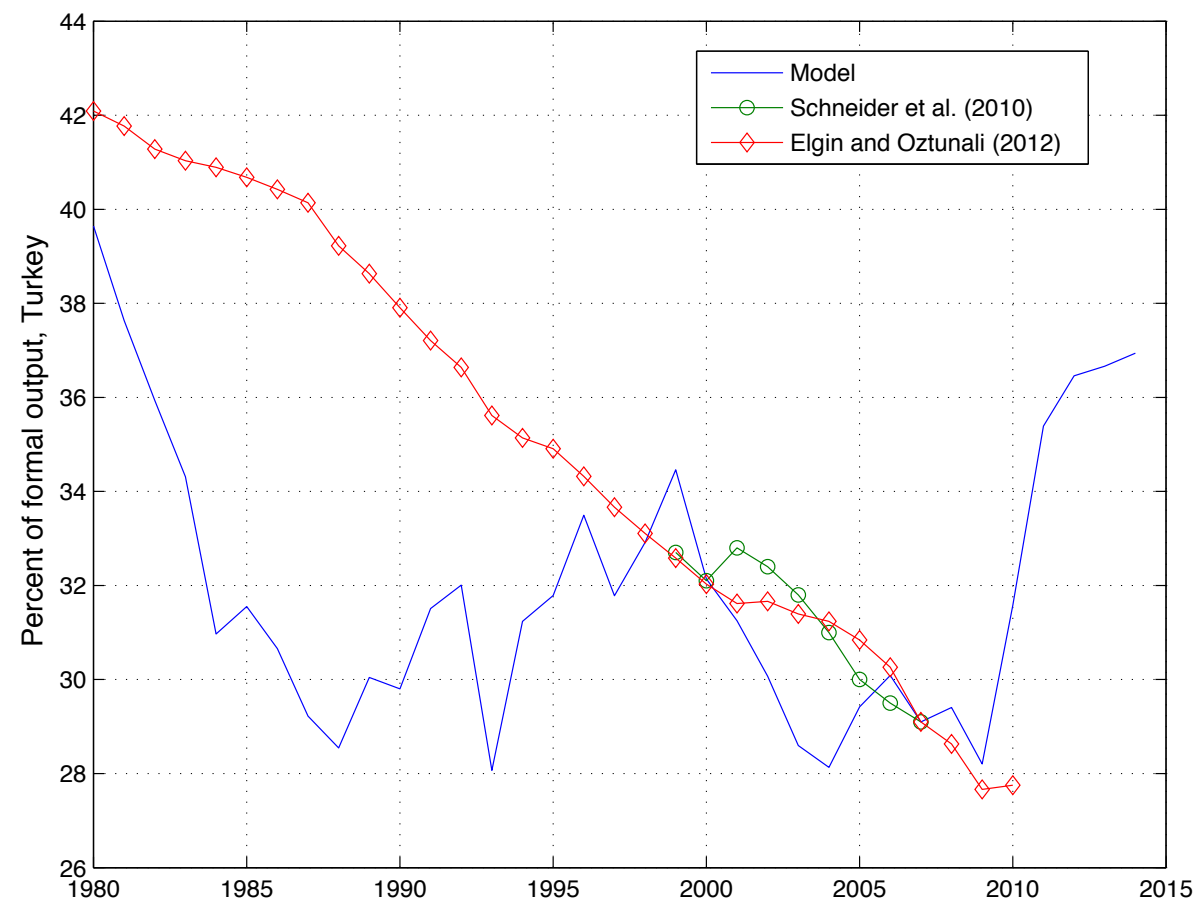

Figure 12: Turkey, shadow-to-formal output ratio, 1980-2014.

the period between 1980 and 1995.

We show the performance of formal and shadow output in Figure 13. Contrary to all the countries discussed previously, Turkish formal output outperforms shadow output throughout the sample. It's interesting to see that the Great Recession has a marked effect in the Turkish economy: while output in both sectors declines and reaches a trough in 2009, the recovery of the shadow sector is considerably faster than that of the formal one.

\section{Vietnam}

We look at the shadow-to-formal output ratio of Vietnam in Figure 14. Our results suggest that the size of the shadow economy has remained small: while it has increased over time (from 8 to $16 \%$ of formal output), this transition has taken place over 35 years. (In fact, the ratio remained stable from 1985 to 2005.)

Also in Figure 14, we see that Schneider et al. show a downward-trending ratio that is not too 


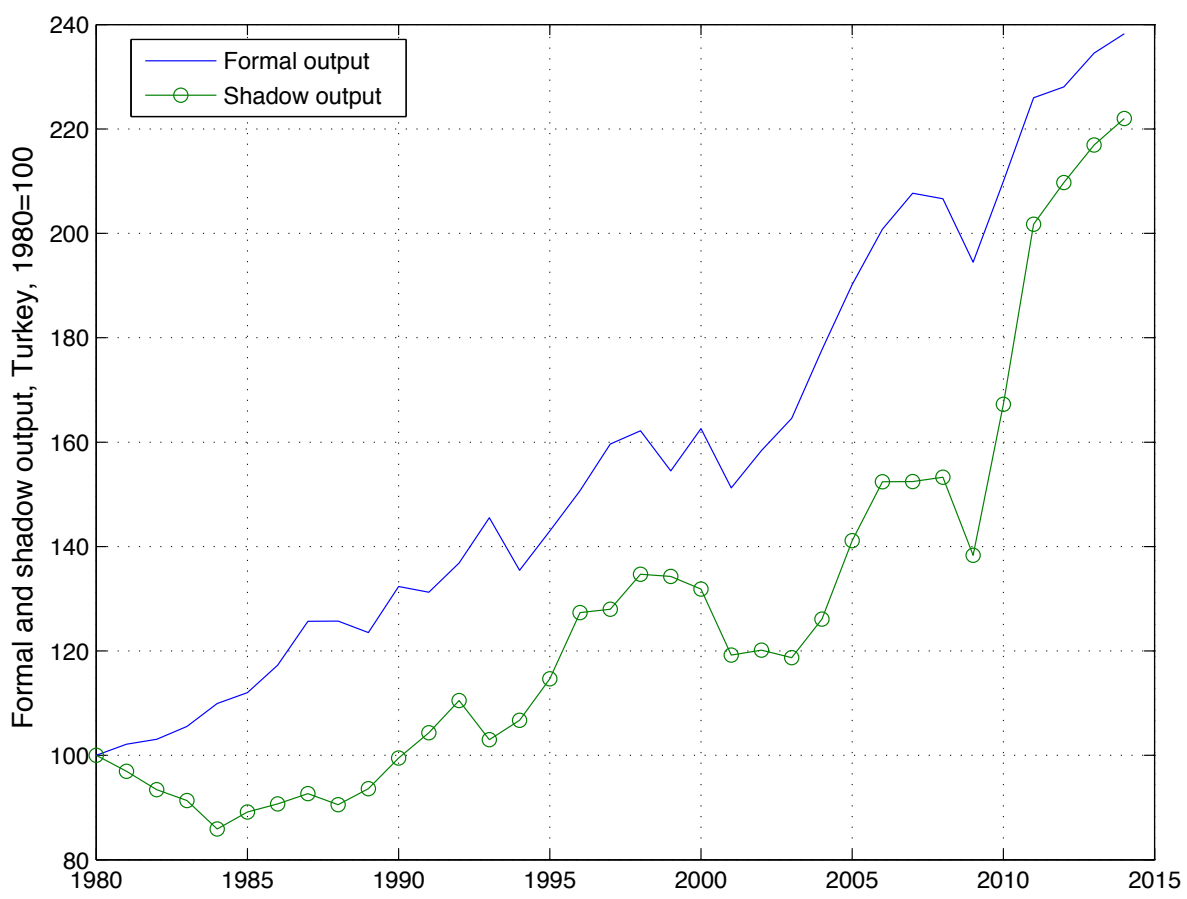

Figure 13: Turkey, formal and shadow output, 1980=100.

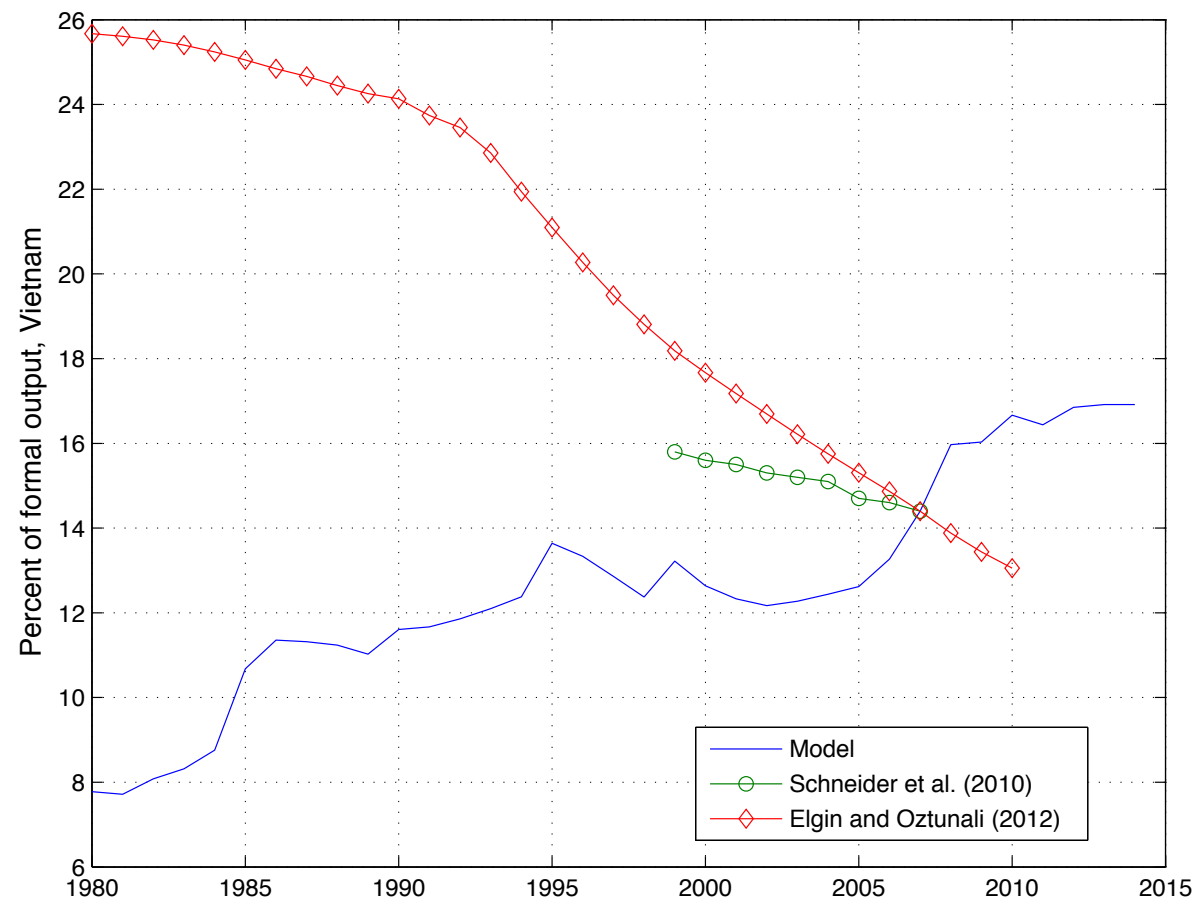

Figure 14: Vietnam, shadow-to-formal output ratio, 1980-2014.

far off from our results. However, the estimates of Elgin and Öztunalı suggest a dramatic decline in the ratio for all the years in their analysis: a slow downward trend from 1980 to 1992 and then 
a steep decline up to 2010 .

The evolution of shadow and formal output in Vietnam looks very similar to that in Indonesia. Figure 15 shows a steady increase in the output produced by both sectors: formal output has increased by a factor of 5 while shadow output has done so by a factor of 11 . It is interesting how shadow output has grown at a faster rate (relative to formal output) after 2005.

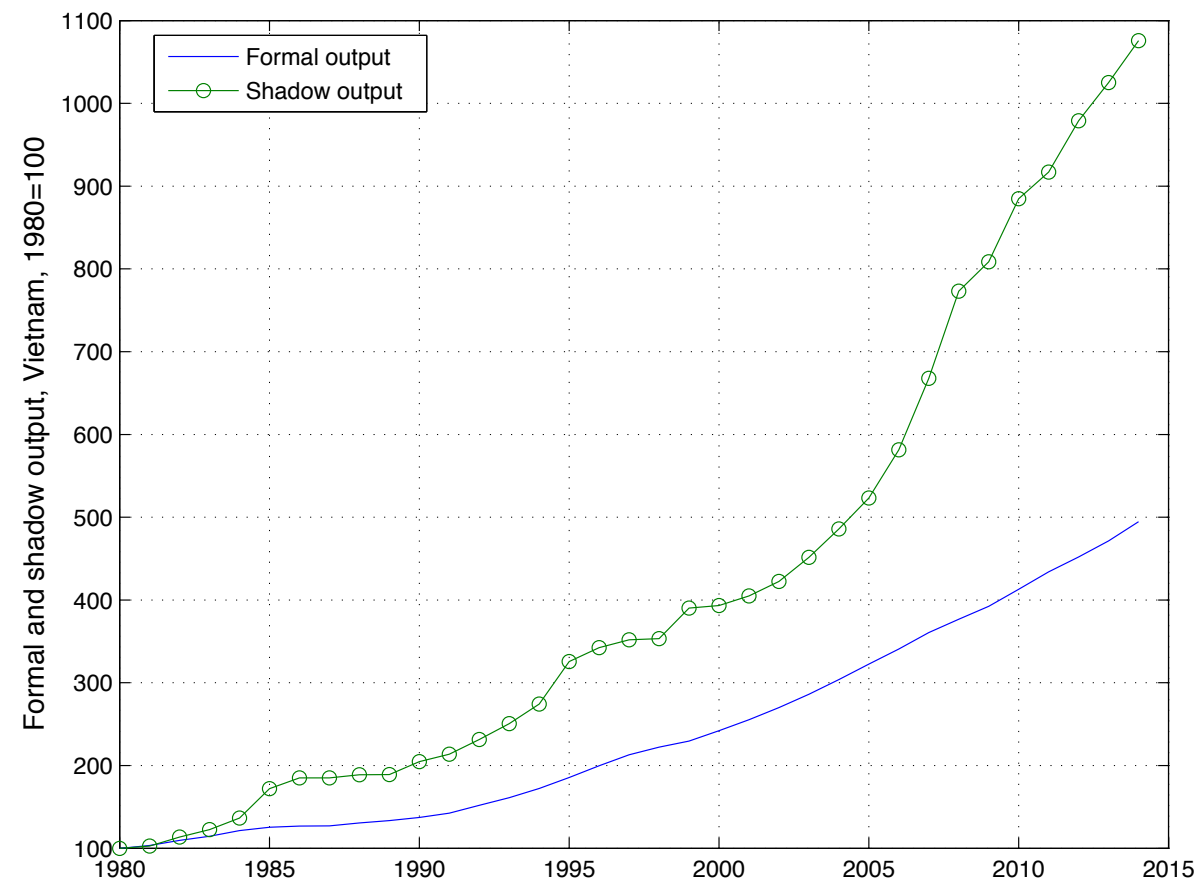

Figure 15: Vietnam, formal and shadow output, 1980=100.

\subsection{Business cycle statistics}

We now present some basic business cycle statistics for all the countries analyzed; in particular, we document the volatilities of shadow, formal, and total output for our sample. We also present some relevant values that are by-products of our methodology: the value for $\eta$, which quantifies the returns to scale in the shadow production function; formal and shadow hours worked in 2007; as well as formal and shadow output per capita for the same year.

We can point to three main features derived from Table 1. First, the standard deviation of the 
Table 1: Business cycle statistics and other relevant values.

\begin{tabular}{lcccccccc}
\hline Country & $\mathrm{SD}\left(Y_{S}\right)$ & $\mathrm{SD}\left(Y_{F}\right)$ & $\mathrm{SD}\left(Y_{\mathrm{TOT}}\right)$ & $\eta$ & $N_{S}$ & $N_{F}$ & $Y_{S}$ & $Y_{F}$ \\
\hline Mexico & 0.0511 & 0.0220 & 0.0264 & 1.33 & 553 & 825 & $\$ 4,553$ & $\$ 15,808$ \\
& & & & & & & & \\
Argentina & 0.0963 & 0.0368 & 0.0439 & 1.39 & 392 & 746 & $\$ 3,911$ & $\$ 17,006$ \\
Brazil & 0.0377 & 0.0202 & 0.0234 & 1.28 & 746 & 874 & $\$ 4,829$ & $\$ 13,193$ \\
Venezuela & 0.0681 & 0.0389 & 0.0438 & 1.39 & 524 & 719 & $\$ 5,929$ & $\$ 19,188$ \\
& & & & & & & & \\
Indonesia & 0.0408 & 0.0233 & 0.0243 & 1.24 & 336 & 895 & $\$ 1,337$ & $\$ 7,470$ \\
Turkey & 0.0438 & 0.0275 & 0.0290 & 1.40 & 410 & 549 & $\$ 4,666$ & $\$ 16,035$ \\
Vietnam & 0.0327 & 0.0085 & 0.0093 & 1.09 & 328 & 1,223 & $\$ 565$ & $\$ 3,923$ \\
& & & & & & & & \\
\hline Average & 0.0529 & 0.0255 & 0.0286 & 1.30 & 470 & 833 & $\$ 3,684$ & $\$ 13,232$ \\
\hline
\end{tabular}

shadow sector output is higher than that of formal sector output for all countries in our sample.

Second, the value of $\eta$ averages 1.3, significantly above the constant returns to scale value of 1 . Finally, hours worked in the shadow sector are smaller than those worked in the formal sector, though for some countries the difference is not that large (see Brazil).

\section{Conclusion}

This paper has developed a methodology to measure the size and properties of the shadow economy. Our methodology is an improvement over other alternatives since (1) our procedure uses the restrictions imposed by a DGE model to estimate the size and dynamics of the shadow economy and (2) it requires minimal data and is relatively easy to implement. We believe that our methodology can prove useful to policymakers and academics interested in the shadow economy.

The work we present in the paper can easily be extended along several dimensions. First, the length of the shadow economy size time series can be used to determine whether developing economies are more volatile than developed ones, after taking the output of the shadow economy into consideration (see Solis-Garcia and Xie 2016a). Second, the data can also be used to elaborate 
on the determinants of the shadow economy (e.g., Friedman, Johnson, Kaufmann, and ZoidoLobatón 2000).

\section{References}

Ceyhun Elgin and Oguz Öztunalı. Shadow economies around the world: model based estimates. Working Paper 2012/05, Boğaziçi University, Department of Economics, 2012.

Robert Feenstra, Robert Inklaar, and Marcel Timmer. The next generation of the Penn World Table. American Economic Review, 105(10):3150-82, 2015.

Andrés Fernández and Felipe Meza. Informal employment and business cycles in emerging economies: the case of Mexico. Review of Economic Dynamics, 18(2):381-405, 2015.

Eric Friedman, Simon Johnson, Daniel Kaufmann, and Pablo Zoido-Lobatón. Dodging the grabbing hand: the determinants of unofficial activity in 69 countries. Journal of Public Economics, 76(3):459-93, 2000.

Pedro Gomis-Porqueras, Adrian Peralta-Alva, and Christopher Waller. The shadow economy as an equilibrium outcome. Journal of Economic Dynamics and Control, 41:1-19, 2014.

György Gyomai and Peter van de Ven. The non-observed economy in the System of National Accounts. Statistics Brief 18, Organisation for Economic Co-operation and Development, June 2014.

Jane Ihrig and Karine Moe. Lurking in the shadows: the informal sector and government policy. Journal of Development Economics, 73(2):541-77, 2004.

Pierre Lafourcade and Joris de Wind. Taking trends seriously in DSGE models: an application to the Dutch economy. Working Paper 345, De Nederlandsche Bank, 2012. 
OECD. Measuring the Non-Observed Economy: A Handbook. Organisation for Economic Cooperation and Development, Paris, 2002.

Renzo Orsi, Davide Raggi, and Francesco Turino. Size, trend, and policy implications of the underground economy. Review of Economic Dynamics, 17(3):417-36, 2014.

Friedrich Schneider and Dominik Enste. Shadow economies: size, causes, and consequences. Journal of Economic Literature, 38(1):77-114, 2000.

Friedrich Schneider, Andreas Buehn, and Claudio Montenegro. Shadow economies all over the world: new estimates for 162 countries from 1999 to 2007. Policy Research Working Paper 5356, World Bank, 2010.

Mario Solis-Garcia and Yingtong Xie. Mismeasured GDP, business cycles, and the shadow economy. Unpublished manuscript, 2016a.

Mario Solis-Garcia and Yingtong Xie. Technical appendix: measuring the size of the shadow economy using a dynamic equilibrium model with trends. Unpublished manuscript, $2016 \mathrm{~b}$.

Karl Whelan. A two-sector approach to modeling U.S. NIPA data. Journal of Money, Credit, and Banking, 35(4):627-56, 2003. 


\section{A Data sources}

From the Penn World Table 9.0 (Feenstra, Inklaar, and Timmer 2015) we obtain the following variables:

1. Real GDP at constant 2011 national prices (rgdpna).

2. Capital stock at constant 2011 national prices (rkna).

3. Share of government consumption at current PPPs (csh_g).

4. Price level of capital formation ( $\left.\mathrm{pl} \_i\right)$.

From The Conference Board ${ }^{11}$ we obtain the following variables:

5. Midyear population.

6. Total annual hours worked.

From the items above, our model variables are obtained as follows:

7. Formal GDP per capita: 1/5.

8. Capital stock per capita: $2 / 5$.

9. Price of investment: 4 .

10. Hours worked per capita: $6 / 5$.

11. Tax rate: 3 .

Finally, the shadow economy size (relative to formal RGDP) is obtained from Elgin and Öztunalı (2012) and from Schneider, Buehn, and Montenegro (2010).

\footnotetext{
11 The source is The Conference Board Total Economy Database ${ }^{\mathrm{TM}}$, May 2016, http://www. conferenceboard.org/data/economydatabase/.
} 


\section{B Proofs}

Proof of Proposition 4.1 First combine (4.1)-(4.10) to get the $4 \times 4$ system

$$
\begin{aligned}
g_{Y} & =g_{A} g_{K} \\
g_{H}\left(g_{N}\right)^{1+\chi} & =g_{Y}^{1-\sigma} \\
g_{Y} & =g_{K}^{\alpha} g_{F}^{1-\alpha} g_{N}^{1-\alpha} \\
g_{Y} & =g_{S}^{\eta} g_{N}^{\eta} .
\end{aligned}
$$

Substitute (B.1) in (B.2) and (B.3):

$$
\begin{aligned}
& g_{H} g_{N}^{1+\chi}=g_{A}^{1-\sigma} g_{K}^{1-\sigma} \\
& g_{A} g_{K}^{1-\alpha}=g_{F}^{1-\alpha} g_{N}^{1-\alpha} .
\end{aligned}
$$

Now solve for $g_{N}$ from (B.6)

$$
g_{N}=g_{A}^{1 /(1-\alpha)} g_{K} g_{F}^{-1}
$$

and plug in (B.5). Solving for $g_{K}$ we get

$$
g_{K}=g_{H}^{-1 /(\sigma+\chi)} g_{A}^{-[\alpha(1-\sigma)+\sigma+\chi] /[(1-\alpha)(\sigma+\chi)]} g_{F}^{(1+\chi) /(\sigma+\chi)},
$$

which is equation (4.11). Now use (B.8) in (B.7) and solve for $g_{N}$ to get

$$
g_{N}=g_{H}^{-1 /(\sigma+\chi)} g_{A}^{-\alpha(1-\sigma) /[(1-\alpha)(\sigma+\chi)]} g_{F}^{(1-\sigma) /(\sigma+\chi)}
$$


which is equation (4.12). Next, use (B.8) in (B.1); collecting common terms yields

$$
g_{Y}=g_{H}^{-1 /(\sigma+\chi)} g_{A}^{-\alpha(1+\chi) /[(1-\alpha)(\sigma+\chi)]} g_{F}^{(1+\chi) /(\sigma+\chi)}
$$

which is equation (4.13). Finally, take (B.4) and substitute (B.9) and (B.10); after some algebra, we find that

$$
g_{S}=g_{H}^{-(1+\eta) /[(\sigma+\chi) \eta]} g_{A}^{-\alpha[1+\chi+(1-\sigma) \eta] /[(1-\alpha)(\sigma+\chi) \eta]} g_{F}^{[1+\chi+(1-\sigma) \eta] /[(\sigma+\chi) \eta]}
$$

as needed.

Proof of Proposition 4.3 Take (B.2) and solve for $g_{H}$ to get (4.15). Take (B.1) and solve for $g_{A}$ to get (4.16). Finally, take (B.3) and solve for $g_{F}$ to get (4.17). 